\title{
Associação entre a síndrome de burnoute a violência ocupacional em professores
}

Association between burnout syndrome and workplace violence in teachers

Relación entre el síndrome de burnouty la violencia laboral en profesores

Beatriz Maria dos Santos Santiago Ribeiro ${ }^{1}$ ib htps://orcid.org/0000-0001-5211-5422

Júlia Trevisan Martins ${ }^{2}$ Đo https:/orcid.org/0000-0001-6383-7981

Aline Aparecida Oliveira Moreira² ${ }^{2}$ inttps://orcid.org/0000-0002-2621-7078

Maria José Quina Galdino ${ }^{3}$ ic https://orcid.org/0000-0001-6709-3502

Maria do Carmo Fernandez Haddad Lourenço ${ }^{2}$ ø https://orcid.org/0000-0001-7564-8563

Rita de Cassia de Marchi Barcelos Dalri1 i https://orcid.org/0000-0002-6575-5426

Como citar: Moreira AA, Galdino MJ, Lourenço MC, Dalri RC. Associação entre a síndrome de burnout e a violência ocupacional em professores. Acta Paul Enferm. 2022;35:eAPE01902.

DOI

http://dx.doi.org/10.37689/acta-ape/2022A001902

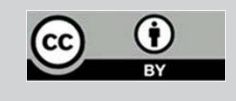

Descritores

Despersonalização; Ensino fundamental e médio; Esgotamento profissional; Docentes; Violência no trabalho

Keywords

Depersonalization; Education, primary and secondary; Burnout, professional; Faculty; Workplace violence

Descriptores

Despersonalización; Educación primaria y secundaria; Burnout, professional; Docentes; Violencia laboral

Submetido 22 de Julho de 2020

Aceito 26 de Maio de 202

Autor correspondente Beatriz Maria dos Santos Santiago Ribeiro E-mail: beatrizsantiago1994@hotmail.com

Editor Associado (Avaliação pelos pares): Juliana de Lima Lopes Escola Paulista de Enfermagem, Universidade Federal de São Paulo, São Paulo, SP, Brasil

\section{Resumo}

Objetivo: Verificar a associação entre a violência laboral e a síndrome de burnout em professores.

Métodos: Estudo transversal realizado com 200 professores do Ensino Fundamental e Médio de um município paranaense. Os dados foram coletados por meio de um instrumento contendo um questionário com dados sociodemográficos, ocupacionais e de caracterização da violência laboral sofrida ou testemunhada nos últimos 12 meses e o Maslach Burnout Inventory para avaliar a síndrome de burnout. Para verificar a relação entre as variáveis dependentes e independentes, utilizou-se 0 coeficiente de correlação de Pearson, 0 teste de Fisher e a regressão linear múltipla. Adotou-se nível de significância de $p$-valor $\leq 0,05$.

Resultados: A prevalência de violência verbal e física foi de $71,5 \%$ e $3 \%$ entre os professores, respectivamente. Verificou-se que $57,5 \%$ apresentaram alta exaustão emocional, 49\% alta despersonalização e 36\% baixa realização profissional, e 21\% possuem indicativo para síndrome de burnout. 0 modelo múltiplo indicou que exaustão emocional e despersonalização estiveram direta e significativamente associadas a sofrer violência física e verbal, bem como presenciar esses tipos de violência, independentemente de sexo e idade.

Conclusão: Os maiores níveis de exaustão emocional e despersonalização estiveram associados à violência sofrida pelos professores. Medidas devem ser tomadas para promover um ambiente laboral mais seguro e, por sua vez, favorecer a saúde física e mental dos professores.

\section{Abstract}

Objective: To verify the association between workplace violence and Burnout Syndrome in teachers.

Methods: This is a cross-sectional study conducted with 200 elementary and high school teachers from a municipality in Paraná. Data were collected through an instrument containing a questionnaire containing sociodemographic, occupational and characterization data of workplace violence suffered or witnessed in the last 12 months and the Maslach Burnout Inventory to evaluate Burnout Syndrome. Pearson's correlation coefficient, Fisher's test and multiple linear regression were used to verify the relationship between dependent and independent variables. A significance level of $p$-value was adopted $\leq 0.05$.

Results: The prevalence of verbal and physical violence was $71.5 \%$ and $3 \%$ among teachers, respectively. It was found that $57.5 \%$ presented high emotional exhaustion, $49 \%$ high depersonalization and $36 \%$ low professional achievement, and 21\% have indicative of Burnout Syndrome. The multiple model indicated that emotional exhaustion and depersonalization were directly and significantly associated with physical and verbal violence, as well as witnessing these types of violence, regardless of gender and age. 
Conclusion: The highest levels of emotional exhaustion and depersonalization were associated with the violence suffered by teachers. Measures should be taken to promote a safer working environment and, in turn, promote the physical and mental health of teachers.

\section{Resumen}

Objetivo: Verificar la relación entre la violencia laboral y el síndrome de burnout en profesores.

Métodos: Estudio transversal realizado con 200 profesores de educación primaria y secundaria de un municipio del estado de Paraná. Los datos fueron recopilados mediante un instrumento con un cuestionario con datos sociodemográficos, laborales y de caracterización de la violencia laboral sufrida 0 presenciada en los últimos 12 meses y el Maslach Burnout Inventory para evaluar el síndrome de burnout. Para verificar la relación entre las variables dependientes e independientes, se utilizó el coeficiente de correlación de Pearson, la prueba de Fischer y la regresión lineal múltiple. El nivel de significación adoptado fue de $p$-valor $\leq 0,05$.

Resultados: La prevalencia de violencia verbal fue del 71,5 \% y física del $3 \%$ entre los profesores. Se verificó que el 57,5 \% presentó agotamiento emocional alto, el 49 \% alta despersonalización y el 36 \% baja realización profesional. El 21 \% tiene indicios de síndrome de burnout. El modelo múltiple indicó que el agotamiento emocional y la despersonalización estuvieron directa y significativamente asociados a sufrir violencia física y verbal, al igual que presenciar estos tipos de violencia, independientemente del sexo y edad.

Conclusión: Los mayores niveles de agotamiento emocional y despersonalización estuvieron relacionados con la violencia sufrida por los profesores. Deben tomarse medidas para promover un ambiente laboral más seguro y, a la vez, favorecer la salud física y mental de los profesores.

\section{Introdução}

A violência sofrida no ambiente laboral causa problemas à saúde física e psíquica dos trabalhadores ${ }^{(1)}$ e apresenta até mesmo relação com a síndrome de burnout. ${ }^{(2)}$ Essa violência pode ser conceituada como qualquer ação em que um profissional, durante o exercício de sua profissão, é vítima de agressão, ameaça ou sofre dano ou lesão no contexto ocupacional. ${ }^{(3)}$ Entre as consequências dela citam-se a redução de força, o adoecimento e o desgaste físico e mental. ${ }^{(1)}$

O professor, na maioria das vezes, está despreparado para se proteger da violência no ambiente escolar, e esta afeta a saúde física e psíquica desses profissionais, como também atinge os alunos, pelos prejuízos ao processo ensino-aprendizagem. ${ }^{(4)}$

O termo burnout representa a descriçáo de exaustáo ou extenuação e é específico do meio laboral; caracteriza-se como resposta prolongada aos estressores interpessoais crônicos. Sua avaliação considera a vivência de estresse determinado por um modelo social, envolvendo três dimensōes: a despersonalização, a exaustáo emocional e a baixa realização profissional. ${ }^{(5)}$

Uma revisão sistemática apontou que os professores do Ensino Fundamental e Médio se configuram entre os profissionais com alto risco para desenvolver a síndrome de burnout. Isso se explica pelo fato de essa profissão se relacionar diretamente com o ser humano e que ao longo do tempo desgasta-se por baixa remuneraçáo, falta de reconhecimento, desmotivação, relaçôes interpessoais conflituosas e violência, entre outros fatores. ${ }^{(6)}$

Pesquisa coordenada pela Organizaçáo para a Cooperação e Desenvolvimento Econômico (OCDE) apontou o Brasil como o país com o maior número de casos de violência imputada contra professores. O estudo, conhecido como Teaching and Learning International Survey (Talis), entrevistou mais de 100 mil professores e diretores de escolas do segundo ciclo do Ensino Fundamental e do Ensino Médio em 34 países. Os dados revelaram que $12,5 \%$ dos entrevistados no Brasil afirmaram ter sofrido agressóes verbais ou de intimidação de alunos pelo menos uma vez por semana, ocupando a pior posição nessa área dentre todos os países pesquisados. A média geral foi de $3,4 \%$, com destaque para Malásia, Romênia e Coreia do Sul, com índice zero de violência contra esses profissionais. ${ }^{(7)}$

Outro estudo ${ }^{(2)}$ mostrou que professores que são vítimas de violência verbal ou física apresentam maiores frequências de níveis elevados de exaustáo emocional e de despersonalização; ou seja, aqueles que sofrem violência laboral têm maiores chances de desenvolver a síndrome de burnout. Autores ${ }^{(8)}$ afirmam que esse cenário dificulta o desenvolvimento de suas atividades, exige grande consumo de energia $\mathrm{e}$, consequentemente, propicia menor eficiência e provoca sentimentos de insatisfação.

Não obstante, o ambiente de trabalho seguro e protegido para todos está preconizado pela agenda da Organização Mundial da Saúde (OMS), em seu relatório "Transformando Nosso Mundo: a Agenda 
2030 para o Desenvolvimento Sustentável”. ${ }^{(9)}$ Assim, os benefícios se voltarão para os próprios trabalhadores, gestores e sociedade, visto que os resultados poderão contribuir para o planejamento de estratégias que visam a diminuir os atos de violências contra os docentes e, dessa maneira, promover a saúde, reduzir os agravos e maximizar a qualidade de vida no trabalho.

Investigar a violência laboral e sua associação com a síndrome de burnout em professores desses níveis de ensino é importante, pois a maioria das pesquisas sobre violência escolar aborda principalmente o bullying; além disso, os estudos com professores tratam, em sua maior parte, a respeito da percepção desse profissional ante a situação de conflito e violência. ${ }^{(10,11)}$ Ainda, autores ${ }^{(11,12)}$ identificam que há lacunas sobre os atos violentos que os docentes sofrem ao realizar suas atividades e que é preciso ampliar o estudo sobre a violência no cotidiano escolar, bem como explorar os diferentes tipos e atores envolvidos no processo, de maneira que seja possível fornecer subsídios com vistas a criar estratégias de enfrentamento. ${ }^{(10)}$

Diante das consideraçóes anteriores, o presente estudo é relevante, visto que ampliar o conhecimento sobre a violência no trabalho e o impacto na saúde dos professores - em especial, os agravos de natureza mental como a síndrome de burnout poderá oferecer subsídios às políticas públicas contra a violência no ambiente escolar. Além disso, os gestores locais, em conjunto com os professores e a comunidade, podem buscar soluçôes para enfrentar essa problemática.

Cabe ressaltar que há um programa nacional de saúde nas escolas cuja finalidade é definir estratégias e formas de produzir saúde, no âmbito individual e coletivo. Ele se caracteriza pela articulação e cooperação intra e intersetorial, buscando integrar suas açôes com as demais redes de proteção social, com ampla participação e controle social. ${ }^{(13)}$ Assim, reforça-se que os resultados do estudo em questáo poderão contribuir com novas possibilidades de atuação da enfermagem no que diz respeito à saúde do trabalhador, pois a violência laboral causa danos principalmente à saúde mental. Desse modo, eles favorecem a reflexão e o planejamento de uma aten- ção holística, multiprofissional a esses profissionais, bem como a possiblidade de inserção a tal programa.

Portanto, este estudo tem como objetivo verificar a associação entre a síndrome de burnout e a violência laboral em professores.

\section{Métodos}

Trata-se de um estudo transversal desenvolvido com professores do Ensino Fundamental e Médio de todas as 18 escolas públicas da zona urbana de um município de médio porte localizado no Estado do Paraná, Brasil. Essa cidade não possui legislação para prevenir atos de violência nas escolas, tampouco um local de acolhimento para professores que sofreram agressão; o que se faz é um Boletim de Ocorrência na Polícia Civil.

No período de coleta de dados, havia 393 professores nas escolas do município; assim, procedeu-se cálculo a fim de se mensurar o tamanho amostral para população finita, levando-se em consideração o desfecho de $50 \%$ e $95 \%$ de intervalo de confiança, o que resultou em número mínimo de 195 profissionais.

Adotou-se como critérios de inclusão professores do Ensino Fundamental e Médio envolvidos no processo de ensino-aprendizagem dos alunos, com contratos efetivos há no mínimo 12 meses. Foram excluídos aqueles que exerciam atividades em outras modalidades (educação especial, educação profissional não articulada ao ensino médio e educação complementar) e os que se encontravam de férias ou em licença de qualquer natureza, o que culminou com a exclusão de 100 docentes. Desta forma, foram convidados os 293 profissionais que estavam aptos a participar deste estudo, dos quais 200 compuseram a amostra. Para identificá-los, anteriormente entrou-se em contato com a direção do Núcleo Regional de Educação do Paraná que autorizou a realização da pesquisa.

O instrumento de coleta de dados foi composto de 52 questóes que incluíram as informaçóes sociodemográficas e laborais, além do questionário de Avaliação da Violência no Trabalho Sofrida ou Testemunhada por Trabalhadores de Enfermagem 
nos últimos 12 meses, que foi elaborado e validado na língua portuguesa brasileira. ${ }^{(14)}$ Após a autorização das pesquisadoras que o elaboraram, ele foi adaptado à realidade dos professores e submetido a uma validação aparente, ${ }^{(15)}$ semelhantemente ao adotado no modelo original.

Assim, o questionário foi avaliado por sete juízes - três educadores, dois psicólogos, um assistente social e um advogado, todos especialistas na área de educação e violência nas escolas. Destaca-se que esse tipo de validação é verificada por meio da avaliação de especialistas e/ou pesquisadores quanto à relevância de um instrumento. ${ }^{(16)}$ Os juízes levaram em consideração a ausência ou presença dos seguintes critérios: abrangência, objetividade, organização e pertinência. ${ }^{(17)}$ Entendeu-se abrangência como atributo da questão que continha informaçóes importantes para o alcance do objetivo do estudo, expressa de maneira compreensível; já objetividade diz respeito à questão de fácil compreensão; a organização, por sua vez, se refere à disposição das questôes e alternativas, bem como também seu conteúdo na ordem sequencial e de fácil resposta; e, por fim, a pertinência como aquela questão essencial para alcançar o objetivo da investigação. ${ }^{(17)}$ Os itens foram considerados adequados quando houve uma concordância mínima de 85,7\% dos avaliadores em relação aos aspectos avaliados. ${ }^{(17)}$

$\mathrm{Na}$ sequência, foi realizado teste-piloto com 41 professores que não faziam parte da população do estudo; eles consideraram o questionário adequado, por isso não houve necessidade de qualquer alteração.

A síndrome de burnout foi medida pelo Maslach Inventory Burnout - Human Services Survey (MBIHSS), uma escala tipo Likert com 22 questóes com respostas que pontuam de zero a seis pontos, dentre as quais nove avaliam a exaustão emocional, cinco, a despersonalização, e oito, a realização profissional. (18) A escolha do MBI-HSS ocorreu pelas características que podem desencadear essa síndrome, bem como por ser um dos instrumentos mais utilizados em todo o mundo, além de apresentar consistência interna e validade fatorial satisfatória com a população de professores brasileiros. ${ }^{(19)}$

Os dados foram coletados nos meses de julho de 2018 e fevereiro de 2019, e isso se deu de duas ma- neiras: nos locais de trabalho durante horário agendado previamente ou por meio de um questionário eletrônico elaborado na plataforma Google Forms, conforme a preferência do professor.

A análise foi realizada no software $\mathrm{R}$ Core Team 2017 e por estatística descritiva, por meio de frequências absolutas, relativas e médias, bem como por estatística inferencial. Para avaliar a consistência interna do MBI-HSS, realizou-se o cálculo do coeficiente alfa de Cronbach. Para determinar a prevalência da síndrome de burnout adotaram-se os seguintes pontos de corte: nível alto $\geq 26$ para exaustão emocional, nível alto $\geq 9$, despersonalização, e baixa realização profissional $\leq 33$. ${ }^{(18)}$

As variáveis dependentes quantitativas intervalares foram: exaustão emocional, despersonalização e realização profissional. Já as variáveis independentes dicotômicas foram: sofrer violência verbal nos últimos 12 meses (sim e não); sofrer violência física nos últimos 12 meses (sim e não); presenciar violência verbal nos últimos 12 meses (sim e não); e presenciar violência física nos últimos 12 meses (sim e não).

Realizou-se a regressão linear múltipla que permite estatisticamente analisar um problema e observar a associação das variáveis, cuja confirmação entre a associação das dimensões da síndrome de burnout e a violência laboral foi realizada pelo teste exato de Fisher. Posteriormente, os modelos múltiplos foram ajustados por idade e sexo. Adotou-se nível de significância o p-valor $\leq 0,05$.

O estudo foi aprovado pelo Comitê de Ética, conforme parecer no 2.744.982 e CAE 87890218.4.0000.5231. As licenças para utilizar o MBI-HSS foram adquiridas da empresa Mind Garden.

\section{Resultados}

Dos 200 professores investigados 77,5\% $(\mathrm{n}=155)$ eram do sexo feminino, 33,5\% $(n=67)$ tinham entre 31 e 40 anos, 76\% (n=152) declararam-se de cor branca, e 35,5\% ( $\mathrm{n}=71)$ não possuíam filhos. No que tange à situação conjugal, $60,5 \%(n=121)$ afirmaram ser casados ou com companheiro, $70 \%$ 
(n = 140) tinham formação ao nível de especialização lato sensu, e 32,5\% $(\mathrm{n}=65)$ possuíam renda individual acima de dez salários mínimos.

A violência verbal, com $71,5 \%(n=143)$, prevaleceu entre a maioria dos professores, e a física ocorreu com 3\% $(n=6)$ deles. A maioria presenciou a violência verbal e a física no trabalho nos últimos 12 meses $(71 \% ; \mathrm{n}=142$ e $39 \% ; \mathrm{n}=78$, respectivamente).

Quanto à consistência interna do MBI-HSS, esta indicou valores satisfatórios para exaustão emocional $(\alpha=0,92)$, despersonalização $(\alpha=0,78)$ e realização profissional $(\alpha=0,81)$, caracterizando boa consistência interna e confiabilidade. Obtiveram-se as médias das três dimensóes do burnout: exaustão emocional (com 29,5), despersonalização $(10,23)$ e realização profissional $(36,07)$.

Embasando-se nos pontos de corte para classificação do MBI-HSS, 57,5\% $(\mathrm{n}=115)$ apresentaram alta exaustão emocional, 49\% ( $\mathrm{n}=98)$, alta despersonalização, e 36\% (n=72), baixa realização profissional. Verificou-se que $21 \%(\mathrm{n}=42)$ possuem indicativo para síndrome de burnout, dos quais $59,5 \%$ $(\mathrm{n}=25)$ são mulheres, 69\% $(\mathrm{n}=29)$ possuem dez anos ou mais de experiência profissional, 57,1\% (n = 24) têm pele branca, 78,5\% (n = 33) não possuem relacionamento conjugal estável, 55,7\% (n = 23) trabalham tempo parcial e não atuam em outra instituição e 66,6\% (n = 28) são docentes em ambas modalidades de ensino (fundamental e médio). Ainda, constatou-se que 53\% $(n=106)$ mostraram alta exaustáo emocional e despersonalização, com propensão a desenvolver a síndrome.

$\mathrm{Na}$ tabela 1, indica-se a ausência de correlação das variáveis de violências com a realização profissional, por meio do coeficiente de correlaçáo de Pearson.

Tabela 1. Correlação da violência laboral com as dimensões do burnout entre professores do Ensino Fundamental e Médio $(n=200)$

\begin{tabular}{|c|c|c|c|c|c|c|}
\hline \multirow[t]{2}{*}{ Variáveis } & \multicolumn{2}{|c|}{$\begin{array}{l}\text { Exaustão } \\
\text { emocional }\end{array}$} & \multicolumn{2}{|c|}{ Despersonalização } & \multicolumn{2}{|c|}{$\begin{array}{l}\text { Realização } \\
\text { profissional }\end{array}$} \\
\hline & $\mathrm{CP}^{*}$ & CVC $\%{ }^{* *}$ & $\mathrm{CP}^{*}$ & CVC $\%{ }^{* *}$ & $\mathrm{CP}^{*}$ & $\mathrm{CVC}^{*{ }^{*+}}$ \\
\hline Violência física & 0,87 & 76,5 & 0,87 & 75,8 & 0,08 & 0,60 \\
\hline $\begin{array}{l}\text { Presenciar violência } \\
\text { física }\end{array}$ & 0,86 & 73,7 & 0,78 & 60,5 & 0,05 & 0,30 \\
\hline Violência verbal & 0,87 & 75,8 & 0,87 & 75,8 & 0,08 & 0,60 \\
\hline $\begin{array}{l}\text { Presenciar violência } \\
\text { verbal }\end{array}$ & 0,87 & 75,7 & 0,83 & 69,0 & 0,05 & 0,20 \\
\hline
\end{tabular}

* CP - coeficiente de correlação de Pearson; *^ CVC - coeficiente de variância compartilhada
Na sequência, examina-se no modelo múltiplo que sofrer violência física e verbal e presenciar violência física e verbal mantiveram associação estatisticamente significativa com exaustão emocional e despersonalização, independentemente de sexo e idade (Tabela 2).

Tabela 2. Associação da síndrome de burnout com a violência laboral entre professores do Ensino Fundamental e Médio $(\mathrm{n}=$ 200)

\begin{tabular}{|c|c|c|c|c|c|}
\hline Modelos* & Estimativa & $\begin{array}{l}\text { Chance } \\
\text { de erro }\end{array}$ & $t$-value & $p$-value & $\begin{array}{c}\text { Intervalo de } \\
\text { confiança de } \\
95 \%\end{array}$ \\
\hline \multicolumn{6}{|l|}{ Exaustão emocional } \\
\hline Violência física & 10,68 & 1,11 & 9,50 & $<0,01$ & $8,48-12,88$ \\
\hline Violência verbal & 12,71 & 0,50 & 23,95 & $<0,01$ & $11,17-13,18$ \\
\hline Presenciar violência física & 15,93 & 0,91 & 17,44 & $<0,01$ & $14,13-17,73$ \\
\hline Presenciar violência verbal & 10,34 & 1,01 & 10,21 & $<0,01$ & $8,34-12,33$ \\
\hline \multicolumn{6}{|l|}{ Despersonalização } \\
\hline Violência física & 5,53 & 0,65 & 8,48 & $<0,01$ & $4,24-6,81$ \\
\hline Violência verbal & 2,28 & 0,29 & 7,68 & $<0,01$ & $1,69-2,86$ \\
\hline Presenciar violência física & 5,51 & 0,53 & 10,34 & $<0,01$ & $4,46-6,56$ \\
\hline Presenciar violência verbal & 7,64 & 0,59 & 12,93 & $<0,01$ & $6,48-6,56$ \\
\hline \multicolumn{6}{|l|}{ Realização profissional } \\
\hline Violência física & 1,70 & 3,69 & 0,73 & 0,46 & $-2,87-6,29$ \\
\hline Violência verbal & 1,77 & 1,33 & 1,33 & 0,18 & $-0,84-4,40$ \\
\hline Presenciar violência física & 0,03 & 1,89 & 0,01 & 0,98 & $-3,71-3,78$ \\
\hline Presenciar violência verbal & $-0,41$ & 2,10 & $-0,19$ & 0,84 & $-4,56-3,74$ \\
\hline
\end{tabular}

Variáveis de ajuste: sexo e idade

\section{Discussão}

No presente estudo, $71,5 \%$ dos professores sofreram violência verbal. Esses dados são análogos ao encontrado na literatura na nacional e internacional, como na pesquisa desenvolvida com docentes do Ensino Médio e Fundamental nos Estados Unidos a qual identificou alto índice de profissionais $(84,8 \%)$ que afirmaram ter sido vítimas de violência verbal de forma direta ou indireta. ${ }^{(20)}$ Estudo realizado em Teresina (Piauí) sobre violência no espaço escolar revelou que metade dos professores do Ensino Médio sofreram atos de violência laboral, as mais frequentes foram os insultos verbais. ${ }^{(10)}$

Em consonância com os dados encontrados no presente estudo, professores que foram vítimas de insultos/gozaçôes de alunos ou violência física exibem maiores frequências de níveis superiores de exaustão emocional e despersonalização, respectivamente. A violência sofrida pode provocar efeitos na saúde física e mental deles, além de tornar o am- 
biente de trabalho dificultoso e intolerável, influenciando para que se sintam ameaçados ao ministrar aulas, desgastando-se nos aspectos físicos, emocionais e cognitivos. ${ }^{(21)}$

$\mathrm{Na}$ investigação em questão pode-se afirmar que a violência física está associada aos níveis da exaustão emocional e de despersonalização. Autores ${ }^{(22)}$ afirmam que a violência ocupacional repercute na saúde física e mental do trabalhador e por consequência em seu bem-estar psicológico. Estudo de revisão realizado na Turquia com a finalidade de revelar a percepção do professor em relação à síndrome de burnout mostrou que esse profissional sabe que ela surge gradativamente a partir de estressores acumulados durante sua rotina de trabalho e que envolve a pressão emocional vivenciada com discentes, pais e colegas de trabalho. ${ }^{(23)}$

A exaustão emocional esteve mais relacionada ao público feminino, semelhantemente ao estudo com professores utilizando-se o modelo de três dimensóes de burnout que revelou a exaustáo emocional maior entre as mulheres. ${ }^{(24)}$ Ainda, pesquisa internacional identificou que mulheres apresentam maior exaustão emocional, maior despersonalização e menor sentimento de realização profissional. ${ }^{(25)}$

Como 77,5\% dos participantes do presente estudo são mulheres, os resultados corroboram com estudo em relação às dimensôes de exaustão emocional e despersonalização, no qual identificou que mulheres apresentaram nos pontos de corte, maiores indicativos para síndrome de burnout do que os homens. ${ }^{(25)}$

De certo modo, a violência no trabalho constitui um preocupante estressor social e uma demanda laboral que esgotam tanto os recursos emocionais como os físicos e consequentemente levam ao burnout, ${ }^{(26)}$ conforme indicou o presente estudo, em que os níveis da síndrome foram associados à exposição à violência.

Os resultados da amostra na presente investigação mostraram que houve associação entre a violência e a síndrome de burnout, assim como ocorreu com o estudo desenvolvido na Polônia que revelou que aqueles que vivenciaram comportamentos agressivos no ambiente escolar relataram sintomas de burnout. ${ }^{(27)}$ No Brasil, averiguou-se relação entre suportar insultos de alunos e exaustão emocional, na qual se associaram ajustes por idade, qualidades do trabalho e percepção de relacionamento com superiores, alunos e família de alunos. A relação da violência com a síndrome de burnout também ficou evidenciada. ${ }^{(2)}$

No estudo em questáo verificou-se que presenciar violência física e verbal teve associação com exaustão emocional e despersonalização, independentemente de sexo e idade. Dados análogos foram encontrados em estudo coreano ao identificar que professores que assistem a atos de violência na escola têm maiores chances de apresentar sofrimento psicológico, de ter mais relacionamentos interpessoais conflituosos, bem como mais elevados níveis de sentimentos de medo, o que, por sua vez, resulta em impactos negativos em seu desempenho laboral. ${ }^{(28)}$

Presenciar a violência física e a verbal associou-se com exaustão emocional e despersonalização entre os professores do estudo em questáo. Pesquisa realizada em Minnesota, nos EUA, com a finalidade de comparar os professores que nunca e os que já presenciaram a violência sendo impetrada contra seus colegas, mostrou que os professores que presenciaram esse ato apresentam maiores chances, isto é, risco quase três vezes maior de sofrer a mesma forma de violência observada no decorres de sua vida. ${ }^{(29)}$

A realização profissional não apresentou associação com as variáveis de violência investigadas, assim como em estudo com professores da educação básica sobre fatores associados a síndrome de burnout, no qual não houve associação da dimensão realização profissional e a violência física. ${ }^{(2)}$

Cabe ressaltar que a violência escolar é um fenômeno social complexo e multifacetado, ao mesmo tempo singular, social e político. No Brasil, dentre as variadas causas, ela é uma ocorrência que perpassa outras formas de violências sociais. ${ }^{(30)}$ A América Latina constitui uma região do mundo em que há maior violência na escola. Tal fato pode estar diretamente relacionado ao de ser um local onde há maior desigualdade econômica/renda, social e educacional, bem como em relação a saúde, saneamento básico, moradia, entre outros. ${ }^{(31)}$

Diante da gravidade das ocorrências de violência no âmbito escolar, a Organização das Nações 
Unidas para a Educação, a Ciência e a Cultura (Unesco) recentemente tem proposto diferentes políticas públicas e culturais com vistas a enfrentar esse problema, já que é uma necessidade de compreender os significados subjacentes aos atos de violência. ${ }^{(32)}$ Assim, é preciso que os gestores, em nível local, estadual e federal, em conjunto com professores, alunos e comunidade da cidade na qual foi realizado o presente em estudo, bem como em outras realidades, busquem ações para diminuir e/ou coibir situaçôes violentas no ambiente escolar.

Destaca-se que a violência não deve ser banalizada ou naturalizada pelas instituiçôes ou grupos de pessoas no trabalho, pois os profissionais que vivenciam esse tipo de situação estão mais propensos à síndrome de burnout. ${ }^{(33)}$ Ela não envolve apenas a vítima e o agressor, mas as relações interpessoais, os aspectos sociais, os históricos e os organizacionais. ${ }^{\left({ }^{34)}\right.}$ Enfatiza-se a importância de as organizaçôes identificarem eventos de violência e assegurarem medidas de políticas e prevenção para o gerenciamento da violência e o esgotamento do trabalhador. ${ }^{(26)}$

Esta pesquisa tem delineamento transversal e náo permite estabelecer relaçóes entre causa $e$ efeito, o que pode ser considerado uma limitaçáo. Entretanto, contribuiu para o avanço do conhecimento científico, em especial da enfermagem, ao propiciar que se repense a saúde do professor para além da concepção biológica, isto é, com uma visão da integralidade. Tal integralidade ocorre quando as açóes implicam o reconhecimento da complexidade, potencialidade e singularidade das pessoas ou grupos, com a finalidade de promover a equidade, maximizar saúde, diminuir as fragilidades de riscos advindos dos determinantes sociais, econômicos, políticos, culturais e ambientais. ${ }^{(13)}$

Dessa forma, a enfermagem do trabalho tem relevante função na prestação de serviços, proteção e promoçáo da saúde para os trabalhadores - professores ou não. Ela pode atuar em integraçáo com equipe multiprofissional e na liderança para o desenvolvimento e o gerenciamento de programas voltados às questôes da violência no âmbito escolar. ${ }^{(35)}$

\section{Conclusão}

Os professores que vivenciaram ou presenciaram violência física e verbal no trabalho nos últimos 12 meses apresentaram maiores níveis de exaustáo emocional e de despersonalização, porém não houve correlaçáo significativa com a realizaçáo profissional. É preciso adotar a cultura de náo aceitar a violência nos ambientes laborais. É necessária uma articulação entre gestores da saúde, educação e, em especial, os das escolas e profissionais da enfermagem para que ações imediatas possam ser tomadas entre os professores que sofreram agressão e têm altos níveis de exaustáo.

\section{Agradecimentos}

Agradecimento à Coordenação de Aperfeiçoamento de Pessoal de Nível Superior (CAPES), pela bolsa de estudo da primeira autora.

\section{Colaborações}

Ribeiro BMS, Martins JT, Moreira AAO, Galdino MJQ, Lourenço MCFH e Dalri RCMB colaboraram com a concepção do projeto, análise e interpretaçáo dos dados, redação do artigo, revisão crítica relevante do conteúdo intelectual e aprovação da versão final a ser publicada.

\section{Referências}

1. Bordignon $\mathrm{M}$, Monteiro Ml. Violence in the workplace in Nursing: consequences overview. Rev Bras Enferm. 2016;69(5):939-42.

2. Koga GK, Melanda FN, Santos HG, Sant'Anna FL, González AD, Mesas $A E$, et al. Fatores associados a piores níveis na escala de burnout em professores da educação básica. Cad Saude Colet. 2015;23(3):26875.

3. Organização Internacional do Trabalho (OIT). Programa conjunto: nueva iniciativa contra la violência laboral em el sector del salud. Genebra: OIT; 2008 [cited 2019 July 20]. Available from: https://www.ilo.org/ global/about-the-ilo/newsroom/news/WCMS_071411/lang--es/index. $\mathrm{htm}$

4. Facci MG. 0 adoecimento do professor frente à violência na escola. Fractal Rev Psicol. 2019;31(2):130-42. 
5. Maslach C, Leiter MP. Understanding the burnout experience: recent research and its implications for psychiatry. World Psychiatry. 2016;15(2):103-11.

6. Diehl L, Marin AH. Adoecimento mental em professores brasileiros: revisão sistemática da literatura. Estudo Inter Psicol. 2016;7(2):64-85.

7. Instituto Nacional de Estudos e Pesquisas Educacionais Anísio Teixeira (INEP). Relatório Nacional: pesquisa internacional sobre ensino e aprendizagem. Brasília (DF): INEP; 2019 [citado 2019 Jul 20]. Disponível em: http://portal.inep.gov.br/informacao-da-publicacao/-/ asset_publisher/6JYIsGMAMkW1/document/id/6726718

8. Levy GC, Sobrinho FP, Souza CA. Síndrome de Burnout em professores da rede pública. Production. 2009;19(3):458-65.

9. Nações Unidas. Asamblea General. Transformar nuestro mundo: la Agenda 2030 para el desarrollo sostenible. Resolution A/RES/70/1. 2015 [cited 2019 July 20]. Available in: https://documentsdds-ny.un.org/doc/UND0C/GEN/N15/291/93/PDF/N1529193. pdf?OpenElement

10. Lima PV, Rodrigues MT, Mascarenhas MD, Gomes KR, Miranda CE, Frota KM. Prevalence and factors associated with violence against high school teachers in Teresina, Piauí, 2016: a crosssectional study. Epidemiol Serv Saúde. 2020;29(1):e2019159.

11. Melanda FN, Santos HG, Salvagioni DA, Mesas AE, Gonzalez AD, Andrade SM. Physical violence against schoolteachers: na analysis using structural equation models. Cad Saude Publica. 2018;34(5): e00079017.

12. Suarez AA, Gelvez JA, Garcia PA. Violencia en contextos escolares: percepción de docentes sobre manifestaciones de violência en instituciones educativas en Cúcuta-Norte de Santander. Rev Psicogente. 2017;20(37):89-98.

13. Brasil. Ministério da Saúde. Portaria $n^{\circ} 2.446$, de 11 de novembro de 2014. Redefine a Política Nacional de Promoção da Saúde (PNPS). Brasília (DF): Ministério da Saúde; 2014 [citado 2020 Out 3]. Disponível em: http://bvsms.saude.gov.br/bvs/saudelegis/gm/2014/ prt2446_11_11_2014.html

14. Bordignon M, Monteiro Ml. Apparent validity of a questionnaire to assess workplace violence. Acta Paul Enferm. 2018;28(6):601-8.

15. Lobiondo-Wood G, Haber J. Nursing research: methods and critical appraisal for evidence-based practice. 8th ed. Saint Louis: Mosby; 2013.

16. Bannigan K, Watson R. Reliability and validity in a nutshell. J Clin Nurs. 2009;18(23):3237-43.

17. Pasquali L. Instrumentação psicológica. Fundamentos e práticas. Porto Alegre: Artmed; 2010.

18. Schaufeli WB, Leiter MP, Maslach C, Jackson SE. Maslach Burnout Inventory ${ }^{\top}$ : instruments and scoring guides. Mind Garden: California; 2012.

19. Carlotto MS, Câmara SG. Análise fatorial do Maslach Burnout Inventory (MBI) em uma amostra de professores de instituições particulares. Psicol Estud. 2004;9(3):499-505.

20. Berlanda S, Fraizzoli M, Cordova F, Pedrazza M. Psychosocial risks and violence against teachers. Is it possible to promote well-being at work? Int J Environ Res Public Health. 2019;16(22):4439.
21. Brasil KC, Legnani VN, Vieira RA. Violência 'na' e 'da' escola: concepções de professores e alunos adolescentes. Linhas Críticas. 2015;21(46):708-26.

22. Verkuil B, Atasayi S, Molendijk ML. Workplace Bullying and Mental Health: A Meta-Analysis on Cross-Sectional and Longitudinal Data. PLoS One. 2015;10(8):e0135225.

23. Sungu $H$. Teacher victimization in Turkey: a review of the news on violence against teachers. Anthropologist. 2015;20(3):694-706.

24. Dalcin L, Carlotto MS. Síndrome de burnout em professores no Brasil: considerações para uma agenda de pesquisa. Psicol Rev. 2017;23(2):745-70.

25. Pu J, Zhou X, Zhu D, Zhong X, Yang L, Wang H, Zhang Y, Fan S, Liu L, Xie P; China Neurologist Association. Gender differences in psychological morbidity, burnout, job stress and job satisfaction among Chinese neurologists: a national cross-sectional study. Psychol Health Med. 2017;22(6):680-692.

26. Allen BC, Holland P, Reynolds R. The effect of bullying on burnout in nurses: the moderating role of psychological detachment. J Adv Nurs. 2015;71(2):381-90.

27. Mościcka-Teske A, Drabek M, Pyżalski J. [Experienced bullying and hostile behavior in the workplace and symptoms of burnout in teachers]. Med Pr. 2014;65(4):535-42. Polish.

28. Moon B, McCluskey J. School-based victimization of teachers in korea: focusing on individual and school characteristics. J Interpers Violence. 2016;31(7):1340-61.

29. Gerberich SG, Nachreiner NM, Ryan AD, Church TR, McGovern PM, Geisser MS, et al. Case-control study of student-perpetrated physical violence against educators. Ann Epidemiol. 2014;24(5):325-32.

30. Giordani JP, Seffner F, Dell'Aglio DD. Violência escolar: percepções de alunos e professores de uma escola pública. Psicol Esc Educ. 2017; 21(1):103-11.

31. Direitoà educação e direitos na educação em perspectiva interdisciplinar. Raniere NB, Alves AL, organizadores. São Paulo: UNESCO, USP; 2018 [citado 2019 Jul 20]. Disponível em: https://crianca.mppr.mp.br/ arquivos/File/publi/unesco/direito_a_educacao_e_direitos_na_ educacao_em_perspectiva_interdisciplinar_2018.pdf

32. United Nations Educational Scientific and Cultural Organization (UNESCO). School violence and bullying: global status report. Paris: Unesco; 2017 [cited 2019 July 20]. Available from: https://unesdoc. unesco.org/ark:/48223/pf0000246970

33. Giorgi G, Mancuso S, Fiz Perez F, Castiello D'Antonio A, Mucci N, Cupelli V, et al. Bullying among nurses and its relationship with burnout and organizational climate. Int J Nurs Pract. 2016;22(2):160-8.

34. Minayo MC, Assis SG, Souza ER. Os múltiplos tentáculos da violência que afeta a saúde. In: Minayo MCS, Assis SG, organizadores. Novas e velhas faces da violência no século XXI: visão da literatura brasileira no campo da saúde. Rio de Janeiro: Fiocruz; 2017. p. 39-61.

35. Rogers B, Kono K, Marziale MH, Peurala M, Radford J, Staun J. International survey of occupational health nurses' roles in multidisciplinary teamwork in occupational health services. Workplace Health Saf. 2014;62(7):274-81. 